\title{
小学数学生活化教学探析
}

\author{
康秀兰 \\ 江西省于都县银坑镇谢坑小学 \\ DOI:10.32629/jief.v2i7.1994
}

[摘 要] 教育改革进程不断推进, 对小学生进行生活化教学已然成为小学教育者的共识。小学生活化教学水平的高低极大地影响着学生对数 学的兴趣、当下的数学成绩以及未来在数学上的造诣。一位优秀的小学数学教育者, 应当在自己的教学工作中, 积极的对生活化教学进行学 习与研究, 提高自己的生活化教育水平, 将数学基础教育与随处可见的生活现象紧密相连, 从而加大学生对数学的喜爱程度, 让学生轻松地 学习数学。

[关键词] 小学数学; 生活化; 现状; 重要性

中图分类号: G623 文献标识码: A

生活化教学是指在生活化的情景下, 提出教学活动中所遇到的问题, 吸引学生解决问题的兴趣, 从而到达传授知识、解答疑惑的目的。生活 化教学是以学生为主体, 教师为辅助者的教学模式, 使学生们真正的成 为接受知识的主动者。小学数学生活化教学是在生活化教学这一大概念 基础上, 将其灵活的运用到小学数学教育中。小学数学教育者们应以小 学生们的认知环境为基础, 辅以自身难以具象的数学专业知识, 使小学 生们积极灵活地运用数学原理解决生活的实际问题。

\section{1 小学数学教学生活化的现状}

1.1 教学过程中应试教学方式依然存在

在多年的教学中, 我发现农村的小学数学教学还有很多做法不符合 新课改的理念。由于应试教育的存在, 在小学教学中, 传统的教学方式 还依然有着不可忽视的生命力。有的教师还是以书本上的知识传授为主, 让学生在学习数学过程中以获得高分为目标。儿童过早的、过度的被老 师按在数学的符号堆里, 知其然不知其所以然。这让很多孩子体会不到 学习的乐趣, 也违背了学习数学的真正目的。

\section{2 部分教师对新课标不够了解}

利用课件教学, 分成小组互动, 部分教师在上课过程中好像用了新 媒体, 课堂活动也很多, 就觉得自己是按照新课标做了。但因教师对新 教材内容编排理解不够, 导致对新教材和新课标把握不足。在小学数学 生活化教学过程中其实是穿新鞋走老路。

\section{2 小学数学教学生活化的重要性}

\section{1 数学教学生活化符合儿童的思维发展特点}

思维能力的发展从动作思维过渡到形象思维, 再过渡到抽象思维。 由于小学生的认知水平和思维的特点, 小学生以形象思维为主。形象思 维有 “透视” 作用, 和抽象思维互补、共振。儿童头脑中的数学往往就 是生活中的再认, 概念从生活实际引入, 问题从实际得出, 最后再回归 现实。学生的数学学习是一种符号化的数学知识和生活实际的经验相结 合的一种学习过程。利用儿童对周围的事物有很大的好奇心，对生活的 问题很感兴趣, 很想了解生活、熟悉生活等特点, 加强数学生活化, 才 能使学生更好地学数学。数学教学与生活联系起来会使学生更喜欢数学, 愿意学数学。

2.2 数学教学生活化遵从数学教学的发展趋势

《数学课程标准》中, 通过加强过程性、体验性目标, 以及对教材、 教学评价等方面的指导, 明确了在教学时要引导学生主动参与, 亲身实 践, 独立思考, 合作探究。从而培养学生获取新知识的能力、分析和解 决实际问题的能力, 以及合作交流的能力, 并且采用多种评价方式, 促 进学生的发展等等方面都作了详细的阐述。这些阐述都说明了小学数学 生活化是数学教学发展的一个必然趋势。为了培养学生的逻辑思维能力, 把课堂教学中的数学知识与现实生活建立起紧密联系, 利用数学思想数 学概念来改造我们的现实生活, 是我们小学数学课堂教学改革的努力方 向。

\section{3 小学数学教学生活化的几点想法}

3.1 深入钻研, 透彻理解新课标、新教材
数学教学生活化的前提条件是透彻理解新课标、新教材, 这也是必 要条件。一节好课, 一定是在透彻理解教材、课标的基础上设计出来的。 只有吃透教材, 才能设计出即联系生活又促进学生掌握知识的课堂活动; 只有真正理解新课标, 才能在教学过程中不走偏、游刃有余。数学这一 学科的知识点是关联密切的, 生活中遇到需要数学知识解决问题一般也 不会是简单的某一个知识点, 每一节课都考验着教师对教材、课标的掌 握情况。

3.2 善于观察, 感受数学与 “生活” 同在

生活中处处有数学。房屋的面积、桌椅的高度、汽车的速度、卫星 的运行、高楼大厦的建设, 从这些或简单或复杂的数学知识中, 见微知 著, 数学知识与我们的日常生活是密切联系, 密不可分的。作为教师, 要培养学生有一双善于发现的眼睛和一颗善于思考的心。引导学生结合 生活实际, 提炼数学知识, 感受数学与 “生活” 同在, 以此来激发学生 学习数学的兴趣, 从而爱上数学, 这也有助于增强学生对数学知识的应 用意识。

3.3 身临其境, 数学教学多 “情景模拟”

为了在学生学习数学知识的同时, 初步接触和逐渐掌握数学思想, 不断增强数学意识, 就必须在数学过程中加强实践活动, 使学生有更多机 会接触生活和生产实践中的数学问题, 认识现实中的问题和数学问题之间 的联系与区别。教材中设计的许多案例都与实际生活有着密切的联系, 教 师在教学时要尽量根据实际情况, 千方百计地创造一些有利于学生学习的 生活情境, 将枯燥乏味的教学内容设计成生活中看得见、摸得着、听得到 的有价值的案例。同时, 在教学过程中, 教师要善于处理教材、调整教材。 为了让教学更加有趣味性, 情景模拟的效果更好, 教师可以适当重组教材 内容, 给数学课本增加 “营养”, 从而更加适合学生发展的数学学习过程, 让学生真正体验到学数学的乐趣, 感受到数学的魅力。

3.4 学以致用, 解决生活中的实际问题

学习数学最终目的就是要把学到的知识应用到实际生活中去。陶行 知说: “教育只有通过生活才能产生作用并真正成为教育。” 数学教学的 成功与否在很大程度上学生能否运用所学知识去解决实际问题。因此, 在实际生活中, 教师要引导学生运用所学的知识和方法研究、探索, 解 决一些简单的实际问题。例如在学生购买学习用品、学校组织植树节活 动、班级室内布置等过程中, 都需要用到數学知识。在很多次的实际应 用后, 不但可以帮助学生增进对知识的理解, 了解知识的价值, 而且可 以增强学生学习和应用数学知识的信心。

\section{[参考文献]}

[1]胡佩玲. 让深度学习走进小学数学课堂——核心素养下小学数学 教学的一点感悟 [J].新课程,2020(34):70.

[2]黄语琪.例谈小学生数学审题能力的培养[J].新课程,2020(34):199.

[3]马林. 学生数学阅读能力的培养策略探析 [J]. 小学科学 (教师 版),2020(08):194. 